\title{
ĐẶC ĐIỂM LÂM SÀNG, HÌNH ẢNH HỌC VÀ KẾT QUẢ PHẪU THUẬT DI DẠNG ĐộNG TĨNH MẠCH TIỂU NÃO
}

\author{
Khổng Ngọc Minh*, Nguyễn Thế Hào**, Phạm Quỳnh Trang** \\ Keywords: Cerebellar arteriovenous malformations

\section{I. ĐĂT VẤN ĐỀ}

TÓM TẮT

Mục đích: Mô tả đặc điểm lâm sàng, chẩn đoán hình ảnh, kết quả phẫu thuât dị dang đông tĩnh mạch tiểu não. Phương pháp nghiên cứu: Nghiên cứu mô tả cắt ngang hồi cứu và tiến cứu 32 trường hợp dị dạng động tînh mạch tiểu não được điều trị tại bệnh viện Bạch Mai từ tháng 6/2018 đến tháng 6/2021. Kết quả: Trong số 32 bệnh nhân, có 14 nam, 18 nữ, độ tuổi trung bình 38 (9-66 tuổi). 26 bệnh nhân (81.3\%) nhập viện với biểu hiện chảy máu. Phân độ SpetzlerMartin: 6 bệnh nhân độ I, 17 bệnh nhân độ II, 8 bệnh nhân độ III, 1 bệnh nhân độ IV. 10 bệnh nhân được mổ cấp cứu, 8 bệnh nhân được nút mạch tiền phẫu. Kết quả sau mổ tốt đat được ở 26 bênh nhân (81.3\%). Kết luận: Dị dạng động tĩnh mạch tiểu não có tỷ lệ chảy máu cao. Các khối dị dang phần lớn có tĩnh mạch dấn lưu sâu, không nằm ở vùng chức năng. Phẫu thuật lấy khối được chỉ định ở hâuu hết các bệnh nhân có dị dạng động tĩnh mạch tiểu não. Tỷ lệ kết quả tốt sau phẫu thuật lấy toàn bộ khối dị dạng đạt được ở hâu hết bệnh nhân.

Tư khoá: Dị dang động tĩnh mạch tiểu não, kết quả phẫu thuật

\section{SUMMARY}

\section{CEREBELLAR ARTERIOVENOUS \\ MALFORMATIONS: CLINICAL, IMAGING FEATURES AND SURGICAL RESULTS}

Objectives: analyzing clinical, imaging features and evaluation of surgical results of cerebellar arteriovenous malformations. Methods: Crosssectional descriptive retrospective and prospective study of 32 cerebellar AVMs underwent surgery in Bach Mai hospital from 6/2018 to 6/2021. Results: 14 males and 18 females with mean age of 38 (9-66 years old). 26 cases $(81,3 \%)$ presented with hemorrhage. Spetzler-Martin grading scale: 6 grade I, 17 grade II, 8 grade III, 1 grade IV. 10 patients required emergent surgery, 8 cases had received embolization before surgery. A favorable neurological outcome was observed in 26 patients $(81,3 \%)$. Conclusions: Cerebellar arteriovenous malformations frequently present with hemorrhage. Cerebellar arteriovenous malformations are more likely to drain deep and less likely to be eloquent. Microsurgery for cerebellar arteriovenous malformations resection is recommended in most cases. Most patients will experience a favorable surgical outcome.

*Trường Đại học Y Hà Nội

**Bênh viển Bach Mai

Chịu trách nhiệm chính: Khổng Ngọc Minh

Email: khongminhhmu@gmail.com

Ngày nhận bài: 17.5.2021

Ngày phản biên khoa họ: 28.6.2021

Ngày duyệt bài: 12.7.2021
Khối di dang động tĩnh mach não là một thương tổn bẩm sinh của hệ thống mạch não, trong đó máu động mạch chạy thẳng vào tĩnh mạch, không qua mạng lưới mao mạch. Dị dạng động tĩnh mạch tiểu não chiếm khoảng 8-15\% ${ }^{1}$ trong tổng số các loại dị dạng động tĩnh mạch não. Dị dạng động tĩnh mạch tiểu não nằm gân với thân não, thường sâu và nguồn nuôi khó tiếp cận. So với dị dạng động tĩnh mạch não trên lều, bệnh nhân dị dạng động tĩnh mạch tiểu não có xu hướng vớ cao hớn với tỷ lệ vỡ hàng năm $\left(8.6 \%{ }^{3}\right.$ so với $2 \%-4 \%{ }^{4}$ của di dạng đông tĩnh mạch não trên lều). Nếu không được điều trị, di dạng động tĩnh mạch tiểu não có thể gây biến chứng vỡ dẫn đến nguy cơ tàn tật và tử vong ca. Mục tiêu của chúng tôi là đánh giá đặc điểm lâm sàng, chẩn đoán hình ảnh, và kết quả phẫu thuật dị dạng động tĩnh mạch tiểu não.

\section{II. Đốl TƯợNG VÀ PHƯƠNG PHÁP NGHIÊN CỨU}

1. Đối tượng nghiên cứu: Gồm 32 bệnh nhân được chẩn đoán là dị dạng động tĩnh mạch tiểu não và được phẫu thuật lấy khối dị dạng tại khoa Phẫu thuật Thân kinh - Bệnh viện Bạch Mai từ tháng 6/2018 đến tháng 6/2021.

\section{Phương pháp nghiên cứu}

2.1. Phương pháp nghiên cứu: mô tả cắt ngang hồi cứu và tiến cứu. Hồi cứu các trường hợp được phẫu thuật trong thời gian tháng 6/2018-6/2020 dựa trên khai thác hồ sơ, phim ảnh. Tiến cứu các trường hợp trong giai đoạn tháng 6/2020-6/2021 dựa trên thăm khám lâm sàng, phim ảnh, đánh giá thực tế trong mổ và khám lại bệnh nhân sau mổ.

\subsection{Tiêu chuẩn lựa chọn}

- Bệnh nhân được chẩn đoán là dị dạng động tĩnh mạch tiểu não, dựa vào hình ảnh trên phim cắt lớp vi tính đa dãy hoặc chụp động mạch não số hoá xoá nền trước mố

- Bênh nhân được phẫu thuật lấy khối dị dạng

- Có kết quả giải phẫu bệnh là dị dạng động tĩnh mạch não

2.3. Tiêu chuẩn loại trư': - Không đủ hồ sơ, phim ảnh, kết quả giải phẫu bệnh

- Bệnh nhân có Glasgow trước mổ dưới 5 điểm

2.4. Các chi tiêu nghiên cứu

- Với mỗi bệnh nhân, đặc điểm lâm sàng 
được đánh giá dựa trên: tuổi, giới, tiền sử, triệu chứng lâm sàng, điểm Glasgow.

- Đặc điểm chẩn đoán hình ảnh: có chảy máu hay khồng trên phim CLVT. Các đặc tính về hình thái, tính chất của khối dị dạng dựa trên phim MSCT hoặc DSA: kích thước, vị trí, mạch nuôi, tĩnh mạch dẫn lưu, phình mạch kèm theo,... Vị trí khối dị dạng động tînh mạch tiểu não được phân thành 5 nhóm dựa trên phân loại của Lawton²: Dưới chẩm, dưới lều tiểu não, thuỳ nhộng, cạnh xương đá, hạnh nhân tiểu não.

- Kết quả điều trị được đánh giá trên lâm sàng bằng thang điểm Rankin sửa đổi (mRS) và được phân thành hai nhóm. mRS $<3$ được coi là kết quả tốt và kết quả xấu với $m R S \geq 3$. Điểm $m R S$ được đánh giá trước mổ và sau mổ một tháng thu thập từ hồ sơ hoăc qua quá trình tái khám. Kết quả phẫu thuật cải thiện được định nghĩa là điểm mRS giảm hoặc không đổi (mRS thay đổi $\leq 0$ ), tình trang xấu đi với mRS thay đổi $>0$.

- Các thông tin thu thâp được nhâp và phân tích theo chương trình phần mềm IBM SPSS Statistics phiên bản 25.0.

\section{KẾT QUẢ NGHIÊN CỨU}

Trong thời gian nghiên cứu có 32 trường hợp là dị dạng động tĩnh mạch tiểu não được phẫu thuật, chiếm $7,3 \%$ tổng số bệnh nhân dị dạng động tĩnh mạch não ở cùng thời kỳ.

\section{1. Đặc điểm lâm sàng}

1.1. Giới: Có 14 nam $(43,8 \%)$ và 18 nũ $(56,2 \%)$

1.2. Tuổi: Thay đổi từ 9 đến 66 tuổi, độ tuổi trung bình là 38 tuổi.

\subsection{Dâu hiêu lâm sàng:}

\begin{tabular}{|c|c|c|}
\hline $\begin{array}{c}\text { Dấu hiệu lầm } \\
\text { sàng }\end{array}$ & $\begin{array}{c}\text { Số bê̂nh } \\
\text { nhẩn }\end{array}$ & Tỷ lệ \% \\
\hline Đau đâu & 24 & 66,7 \\
\hline Chóng mă̆t & 14 & 43,8 \\
\hline Rối loạn ýthức & 19 & 59,4 \\
\hline Liệt vận động & 1 & 3,1 \\
\hline Co giật & 0 & 0 \\
\hline
\end{tabular}

Đau đâu, chóng mặt, rối loan ý thức là những triệu chứng thường gặp nhất. Không có bệnh nhân nào có triệu chứng co giật.

\section{2. Đăc điểm chẩn đoán hình ảnh:}

\section{1. Đặc điểm chảy máu:}

\begin{tabular}{|c|c|c|}
\hline Đặc điểm chảy máu & Số lượng & Tỷ lệ \% \\
\hline Chảy máu & $\mathbf{2 6}$ & $\mathbf{8 1 , 3}$ \\
Chảy máu nhu mô & 25 & 78,1 \\
Chảy máu não thất & 6 & 18,7 \\
Chảy máu dưới nhện & 7 & 21,9 \\
\hline Không & $\mathbf{6}$ & $\mathbf{1 8 , 7}$ \\
\hline
\end{tabular}

Có 26 bệnh nhân $(81,3 \%)$ nhập viện có biểu hiện chảy máu.
2.2. Đặc điểm hinh thái khôi di dang:

- Kích thước khối dị dạng động tînh mạch tiểu não trung bình là $2,7 \mathrm{~cm}(1,2-5,2)$.

- Môt số đăc điểm khác:

\begin{tabular}{|c|c|c|}
\hline Đặc điểm & Số lượng & Tỷ lệ \% \\
\hline Vùng chức năng & 3 & $9,4 \%$ \\
\hline Tĩnh mạch dân lưu sâu & 19 & $59,4 \%$ \\
\hline Khối lan toả & 23 & $71,9 \%$ \\
\hline
\end{tabular}

- 3 bệnh nhân $(9,4 \%)$ có khối dị dạng nằm ở vùng chức năng. Phần lớn các khối dị dạng có tĩnh mạch dẫn lưu sâu $(59,4 \%)$ và có tính chất lan toả $(71,9 \%)$.

2.3. Phân đô của Spetzler-Martin:

\begin{tabular}{|c|c|c|}
\hline Phân độ & Số bệnh nhân & Tý lệ \% \\
\hline I & 6 & $18,8 \%$ \\
\hline II & 17 & $53,1 \%$ \\
\hline III & 8 & $25,0 \%$ \\
\hline IV & 1 & $3,1 \%$ \\
\hline V & 0 & $0 \%$ \\
\hline
\end{tabular}

Độ II gặp nhiều nhất với 53,1\%. Không có trường hợp nào độ $\mathrm{V}$.

2.4. Vị trí khối dị dạng động tĩnh mạch tiểu não:

\begin{tabular}{|c|c|c|}
\hline $\begin{array}{c}\text { Vị trí khối dị } \\
\text { dạng }\end{array}$ & $\begin{array}{c}\text { Số bê̂nh } \\
\text { nhẩn }\end{array}$ & Tỷ lệ \% \\
\hline Dưới chấm & 7 & $21,9 \%$ \\
\hline Dưới lều tiếu não & 8 & $25,0 \%$ \\
\hline Thuỳ nhộng & 9 & $28,1 \%$ \\
\hline Cạnh xương đá & 7 & $21,9 \%$ \\
\hline Hạnh nhân & 1 & $3,1 \%$ \\
\hline Tống & $\mathbf{3 2}$ & $\mathbf{1 0 0 \%}$ \\
\hline
\end{tabular}

Vị trí thuỳ nhộng tiểu não gă̆p nhiều nhất với tỷ lệ $28,1 \%$.

Hình ảnh khối dị dạng động tĩnh mạch tiểu não vị trí dưới chẩm đã vỡ

\section{Kết quả phẫu thuật}

3.1. Các phương pháp phẫu thuật

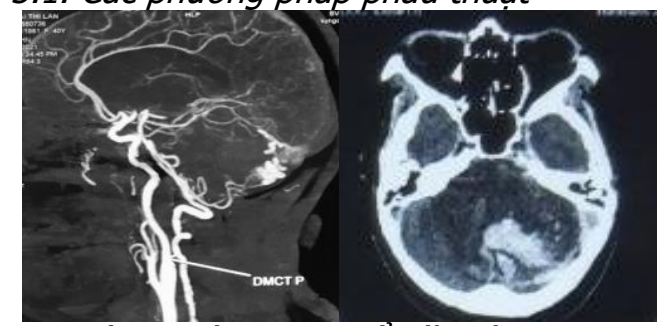

- 10 bênh nhân được mổ cấp cứu (31,3\%)

+3 bệnh nhân được dẫn lưu não thất ra ngoài và lấy khối dị dạng ở thì hai $(9,4 \%)$

+ 7 bệnh nhân được lây máu tụ và khối dị dạng ngay trong một thì (21,9\%)

- 14 bệnh nhân được phẫu thuật lấy khối dị dạng theo chương trình $(43,8 \%)$

- 8 bệnh nhân được điều trị phối hợp nút mạch và phẫu thuật (25\%)

3.2. Các đường mở so

Trong nghiên cứu của chúng tôi, có 7 đường 
mở sọ được sử dụng cho dị dạng động tĩnh mạch tiểu não, bao gồm: dưới chẩm đường bên, dưới chẩm đường giữa, quanh hội lưu, sau xoang xích-ma và một số đường phối hợp.

\subsection{Kết quả phẫu thuât:}

\begin{tabular}{|c|c|c|c|c|c|c|c|c|c|c|c|c|}
\hline \multirow{2}{*}{$\begin{array}{l}\text { Đường } \\
\text { mở sọ }\end{array}$} & \multicolumn{2}{|c|}{ Tổng } & \multicolumn{2}{|c|}{$\begin{array}{l}\text { Dưới } \\
\text { chẩm }\end{array}$} & \multicolumn{2}{|c|}{ Dưới lều } & \multicolumn{2}{|c|}{$\begin{array}{c}\text { Thuỳ } \\
\text { nhộng }\end{array}$} & \multicolumn{2}{|c|}{$\begin{array}{l}\text { Cạnh } \\
\text { xướng đá }\end{array}$} & \multicolumn{2}{|c|}{$\begin{array}{l}\text { Hạnh } \\
\text { nhân }\end{array}$} \\
\hline & $\mathbf{n}$ & $\%$ & $\mathbf{n}$ & $\%$ & 1 & $\%$ & $\mathbf{n}$ & $\%$ & $\mathbf{n}$ & $\%$ & $\mathbf{n}$ & $\%$ \\
\hline Tổng & 32 & 100 & 7 & 21,9 & & 25,0 & & 28,1 & 7 & 21,9 & 4 & 3,1 \\
\hline Dưới chẩm, đườ & 4 & & & 14,3 & & 0 & . & 22,2 & 0 & 0 & 1 & 100 \\
\hline Dưới chẩm, đường bên & 4 & & & 57,1 & & & & 0 & & 0 & & 0 \\
\hline Quanh hội lưu & 12 & 3 & 0 & 0 & 6 & 75,0 & & 66,7 & 0 & 0 & 0 & 0 \\
\hline Sau xoang xích-ma & 4 & 12 & U & 0 & ( & 0 & $U$ & 0 & 4 & 57,1 & U & 0 \\
\hline $\begin{array}{c}\text { Dưới chấm-Sau xoang } \\
\text { xích-ma }\end{array}$ & 2 & 3 & 2 & 28,6 & 0 & 0 & 0 & 0 & 0 & 0 & 0 & 0 \\
\hline $\begin{array}{c}\text { Quanh hô̂i lưu-xoang } \\
\text { xích-ma }\end{array}$ & 3 & 9,4 & 0 & 0 & 2 & 0 & 1 & 11,1 & 0 & 0 & 0 & 0 \\
\hline $\begin{array}{c}\text { Sau xoang xích-ma mở } \\
\text { rộng }\end{array}$ & 3 & 9,4 & 0 & 0 & 0 & 0 & 0 & 0 & 3 & 42,9 & 0 & 0 \\
\hline
\end{tabular}

Có 26 bệnh nhân có kết quả tốt sau phẫu thuật đạt $81,3 \%$. 6 bệnh nhân còn lại có kết quả xấu (mRS 3-6 điểm), trong đó bệnh nhân có kết quả xấu nhất (mRS 5 điểm) có tình trạng lâm sàng nặng khi nhập viện, hôn mê Glasgow 8 điểm, phim chụp có hình chảy chảy máu tiểu não lớn cùng chảy máu não thất, cần phải mổ cấp cứu dẫn lưu não thất ra ngoài. Sau phẫu thuật có 29/32 bệnh nhân có tình trạng lâm sàng cải thiện ( $m R S$ thay đổi $\leq 0$ ).

Tất cả các bệnh nhân sau mổ đều được chụp MSCT hoặc DSA kiểm tra. Không có trường hợp nào ghi nhận còn tồn dư khối dị dạng.

\section{BÀN LUÂ̂N}

1. Đặc điểm lâm sang. Nghiên cứu của chúng tổi bao gồm 32 bệnh nhân dị dạng động tĩnh mạch tiểu não được phẫu thuật, chiếm 7,3\% tất cả các loại dị dạng động tĩnh mạch não trong khoảng thời gian nghiên cứu. Bệnh nhân dị dạng động tînh mạch tiểu não có tỷ lệ biểu hiện chảy máu khi nhập viện cao (81,3\%), tương đồng với một số nghiên cứu trước đây (78\%$\left.88 \%^{2}\right)$. Tỷ lệ này cao hơn đáng kể so với khối dị dạng trên lều $\left(38 \%-68 \%{ }^{4}\right)$. Việc phát hiện khi đã vỡ dẫn đến bệnh nhân có mức độ tàn tật, tử vong cao hơn ${ }^{5}$.

Một sự khác biệt quan trọng giữa dị dạng động tĩnh mạch ở tiểu não so với trên lều là bệnh nhân dị dạng động tĩnh mạch tiểu não không có biểu hiện co giật. Trong khi đó, tỷ lệ biểu hiện co giật của dị dạng động tĩnh mạch trên lều là $17 \%-30 \%{ }^{6}$, xấp xỉ mức chênh lệch tỷ lệ biểu hiện chảy máu giữa dị dạng động tĩnh mạch tiểu não và trên lều. Vì vậy, có lẽ tỷ lệ biểu hiện chảy máu cao của dị dạng động tĩnh mạch tiểu não so với trên lều không phụ thuộc vào đặc điểm hình thái mà do đặc điểm lâm sàng không biểu hiện co giật. Dù là nguyên nhân nào, tỷ lệ biểu hiện chảy máu cao của dị dạng động tĩnh mach tiểu não yêu cầu môt chiến lược điêu trị tích cực hơn, chỉ định mổ lấy khối dị dạng rộng rãi hơn.

2. Đặc điểm chẩn đoán hình ảnh. Trong nghiên cứu của chúng tôi, các bệnh nhân dị dạng động tĩnh mạch tiểu não có kích thước khối dị dạng trung bình $2,7 \mathrm{~cm}$, và không có bệnh nhân nào có khối dị dạng lớn hơn $6 \mathrm{~cm}$. Đối với dị dạng động tĩnh mạch tiểu não ngoại trừ các tînh mạch bán cầu tiểu não đổ trực tiếp về xoang dọc trên hoặc xoang ngang thì đều là các tĩnh mạch dẫn lưu sâu. Nên các tĩnh mach dẫn lưu sâu chiếm ưu thế với 59,4\%. Chỉ các nhân sâu tiểu não và cuống tiểu não được coi là vùng chức năng, nên chỉ có $3 / 32$ bệnh nhân $(9,4 \%)$ có khối dị dạng nằm ở vùng chức năng. Với xu hướng kích thước không lớn, và phần lớn không nằm ở vùng chức năng dẫn đến phân độ theo Spetzler-Martin hầu như không có khối dị dạng độ $V$ và rất ít khối dị dạng độ IV. Ở nghiển cứu của chúng tôi không có trường hợp nào phân độ V. Tương đồng với kết quả nghiên cứu của Rodrıguez-Hernandez 2012². Dị dạng động tĩnh mạch tiểu não thường có nguồn nuôi là các động mạch sâu, khó tiếp cận và thường có tính chất lan toả gây khó khăn trong quá trình phẫu thuật.

3. Kết quả phẫu thuật. Chỉ định mổ với dị dạng động tĩnh mạch ở tiểu não theo y văn rộng rãi hơn so với trên lều cả với khối dị dạng đã võ̃ hay chưa võ do xu hướng chảy máu cao và hiếm khi nằm ở vùng chứng năng. Chỉ định nút mạch tiền phẫu với những trường hợp khối dị dạng lan 
toả hoặc có nguồn động mạch nuôi ở sâu khó tiếp cận từ đâu cuộc mổ. Những khối dị dạng vị trí dưới lều hoặc phần trên của thuỳ nhộng có nguồn cấp máu chính từ động mạch tiểu não trên và động mạch não sau, nên thường ở vị trí sâu và khó tiếp cận nhất trong trường mổ. Nếu được nút mạch tiền phẫu những động mạch này thì cuộc mổ sẽ an toàn hơn.

Đường mở sọ trong phẫu thuật dị dạng động tĩnh mạch tiểu não cũng tuân theo nguyên tắc rộng rãi, đảm bảo tiếp cận tối đa ổ dị dạng và các nguồn động mạch nuôi và tĩnh mạch dấn lưu. Đặc điểm vùng hố sau là trường mổ hep và sâu nển với mỗi ca bệnh, phẫu thuật viên cần nghiên cứu kỹ vị trí khối và các nguồn động mạch nuôi chính để xác định đường tiếp cận phù hợp.

Trong nghiên cứu của chúng tôi, kết quả phẫu thuật đị dạng động tĩnh mạch tiểu não tốt chiểm tỳ lệ cao (81,3\%). 6 trường hợp có kết quả phẫu thuật không tốt đều có tình trạng lâm sàng trước mổ nặng tri giác khi nhập viện kém. Tỷ lệ lâm sàng không cải thiện so với trước mổ thấp, chỉ $3 / 32$ trường hợp $(9,4 \%)$. Các nghiên cứu trước đây cũng cho kết quả tương đồng với tỷ lệ kết quả phẫu thuật tốt cao $(65 \%-78 \%)^{2}$ và tỷ lệ lâm sàng không cải thiện sau mổ thấp $(20 \%-24 \%)^{2}$.

\section{KẾT LUÂN}

Dị dạng động tĩnh mạch tiểu não có biểu hiện lâm sàng khác so với dị dạng động tĩnh mạch trên lều với nổi trội là tỷ lệ biểu hiện chảy máu cao, không có biểu hiện co giật... Các khối dị dạng động tĩnh mạch tiểu não thường có kích thước trung bình, tĩnh mạch dẫn lưu sâu, không nằm ở vùng chức năng và thường có tính chất lan toả. Dị dạng động tînh mạch tiểu não thường là các tổn thương sâu, khó tiếp cận, gần với các cấu trúc giải phẫu quan trọng như thân não, các dây thần kinh sọ, các xoang tĩnh mạch. Phẫu thuật lấy khối được chỉ định ở hầu hết các bệnh nhân dị dạng động tĩnh mạch tiểu não. Kết quả phẫu thuật tốt chiểm tỷ lệ cao.

\section{TÀI LIẸU THAM KHẢO}

1. Robert T, Blanc R, Ciccio G, et al. Anatomic and angiographic findings of cerebellar arteriovenous malformations: Report of a single center experience. J Neurol Sci. 2015;358(12):357-361. doi:10.1016/j.jns.2015.09.361

2. Rodríguez-Hernández A, Kim $\mathbf{H}_{\text {, }}$ Pourmohamad $T$, Young WL, Lawton $M T$, University of California, San Francisco Arteriovenous Malformation Study Project. Cerebellar arteriovenous malformations: anatomic subtypes, surgical results, and increased predictive accuracy of the supplementary grading system. Neurosurgery. $2012 ; 71(6): 1111-1124$. doi:10.1227/NEU.0b013e318271c081

3. Tong $\mathbf{X}, \mathbf{W u} \mathbf{J}$, Lin $\mathbf{F}$, et al. Risk Factors for Subsequent Hemorrhage in Patients with Cerebellar Arteriovenous Malformations. World Neurosurg. doi:10.1016/j.wneu.2016.04.082

2016:92:47-57.

4. Ozpinar A, Mendez G, Abla AA. Epidemiology, genetics, pathophysiology, and prognostic classifications of cerebral arteriovenous malformations. In: Handbook of Clinical Neurology. Vol 143. Elsevier; 2017:5-13. doi:10.1016/B978-0444-63640-9.00001-1

5. da Costa L, Thines L, Dehdashti AR, et al. Management and clinical outcome of posterior fossa arteriovenous malformations: report on a single-centre 15-year experience. J Neurol Neurosurg Psychiatry. 2009;80(4):376-379. doi:10.1136/jnnp.2008.152710

6. Can A, Gross BA, Du R. The natural history of cerebral arteriovenous malformations. In: Handbook of Clinical Neurology. Vol 143. Elsevier; 2017:15-24.doi:10.1016/B978-0-444-63640-9.00002-3

\section{KẾT QUẢ PHẪU THUÂTT VẾT THƯƠNG SỌ NÃO TẠI BÊ̂NH VIỆN ĐA KHOA TİNH THÁI BÌNH}

\section{TÓM TẮT}

Mục tiêu: Nhận xét kết quả phẫu thuật vết thương sọ não tại bệnh viện Đa khoa tỉnh Thái Bình.

\footnotetext{
*Trường Đại học Y Dược Thái Bình Chịu trách nhiệm chính: Vũ Minh Hải Email: vuminhhai777@gmail.com Ngày nhận bài: 14.5.2021 Ngày phản biện khoa học: 29.6.2021 Ngày duyệt bài: 12.7.2021
}

\section{Vũ Minh Hải*, Dương Như Năm*, Vũ Minh Hải (1981)*}

Phương pháp: Nghiên cứu mô tả 39 bệnh nhân vết thương sọ não điều trị tại Bệnh viện Đa khoa tỉnh Thái Bình trong thời gian từ tháng 1 năm 2017 đến tháng 6 năm 2019. Kết quả: 39 bệnh nhân gồm 35 nam $(89,7 \%)$ và 4 nữ $(10,3 \%)$; nguyên nhân do tai nan giao thông gặp nhiêu nhất $(64,1 \%)$, bạo lực chiếm $(17,9 \%)$. Tri giác của bệnh nhân khi vào viền nhóm GCS $\leq 8$ điểm chiếm ( $5,1 \%)$, GCS: $9-12$ điểm chiếm $(10,3 \%)$, GCS: $13-15$ điểm chiếm $84,6 \%$. Lâm sàng vết thương chảy dịch não tủy $(7,7 \%)$, tổ chức não tại vết thương $(7,7 \%)$. Dị vật bẩn đất, cát, tóc chiếm $56,4 \%$. Máu tụ trong sọ đi kèm vết thương sọ não chủ 